\title{
Über «Plugs», «Tunnels» und «Freestyles»
}

Wolff, Eberhard

DOI: https://doi.org/10.4414/saez.2018.06752

Posted at the Zurich Open Repository and Archive, University of Zurich ZORA URL: https://doi.org/10.5167/uzh-159221

Journal Article

Published Version

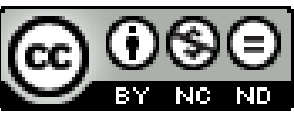

The following work is licensed under a Creative Commons: Attribution-NonCommercial-NoDerivatives 4.0 International (CC BY-NC-ND 4.0) License.

Originally published at:

Wolff, Eberhard (2018). Über «Plugs», «Tunnels» und «Freestyles». Schweizerische Ärztezeitung (SÄZ), 99(25):850.

DOI: https://doi.org/10.4414/saez.2018.06752 


\section{Über «Plugs», «Tunnels» und «Freestyles»}

\section{Eberhard Wolff}

Prof. Dr. rer. soc., Redaktor Kultur, Geschichte, Gesellschaft

Eindrucksvoll sehen sie auf jeden Fall aus. Die «Plugs», die grosse, immer grösser gedehnte Löcher in den Ohrläppchen füllen. Oder die «Tunnels», die mächtige Ohrläppchenlöcher ringförmig umranden. Ob wir Älteren diese "geweiteten Piercings» schön finden, steht hier nicht zur Debatte. Die allgemeinen Umgangsformen mit unseren Körpern haben sich dafür in den letzten Jahren viel zu drastisch und vielfältig verändert: mit Piercings genauso wie mit trainierten Muskeln, mit Tattoos genauso wie mit Botox. Die ästhetischen Standards ändern sich. Und wir uns mit ihnen.

In diesem Frühling ist mir ein anderer Körperschmuck mehrfach aufgefallen: Es ist eine etwa zweifrankengrosse Scheibe, die frei an der Hinterseite des Oberarms zu schweben scheint - aus eierschalenfarbenem Kunststoff, mit einer Umrandung und einem Punkt in der Mitte. Ästhetisch und diskret - wie ein kleines Tattoo. Haben Sie das auch schon gesehen? Beziehungsweise: Dämmert Ihnen etwas?

Im Ernst: Als mir so ein Ding das erste Mal beim Bäcker an der Frau vor mir in der Schlange aufgefallen ist, wusste ich es nicht sofort zuzuordnen: Schmuck oder medizinisches Gerät? Natürlich hatte ich von den vielen neuen Techniken gehört, den Glukose-Gehalt des Blutes ohne schmerzhaften Pieks zu messen: Implantat, Techno-Kontaktlinse, Digital-Pflaster, alles in unterschiedlichen Entwicklungsstufen. Nun breitet sich «Freestyle Libre» (so der Name des Oberarm-Plättchens) in der Schweiz offenbar rasant aus. Ein aufgeklebtes diagnostisches High-Tech-Gerät von Abbott für Diabetiker, das den Glukosespiegel der interstitiellen Flüssigkeit mit einer kleinen Nadel in den obersten Hautschichten misst. Das kurz hingehaltene Lesegerät ruft die Werte ab und zeigt sie auf einem Bildschirm an. Nach zwei Wochen hat die Scheibe ausgedient. Ich nehme an, sie wird neben den Nespresso-Kapseln recycelt.

Dass das Ding nun auch an schweizerischen Oberarmen gehäuft auftritt, hat natürlich damit zu tun, dass es seit letzten Sommer bei uns kassenzulässig ist. Ich denke aber, dass dahinter auch ein gewandelter Umgang mit dem Körper, der Haut und mit Krankheiten steckt.

Die Scheibe, die ihre Träger(innen) als diabetisch identifiziert, wird ganz offen und selbstverständlich getragen. Krankheit wird damit selbstbewusster und öffentlicher gelebt, als es bei den doch meist diskret durchgeführten Pieks-Messungen üblich war. Auch der Rollator scheint mir in letzter Zeit weniger als Kainsmal der Gebrechlichkeit verstanden zu werden denn als Ausdruck einer Selbstbehauptung im öffentlichen Leben unter erschwerten Bedingungen.

Die Grenze zwischen Körper und Technik verschwimmt zusehends. Auf den letztjährigen Trendtagen Gesundheit implantierte die Firma Digiwell kleine Funkchips unter die Haut, und das wurde als etwas Skurril-Verspieltes wahrgenommen. Dabei hatte ihr Vertreter Patrick Kramer in aller Deutlichkeit klar gemacht, dass wir seit Langem mit zunehmendem Alter zu Mensch-Technik-Cyborgs werden, mit Hörgeräten, Hüftgelenken, Herzschrittmachern. Der Glukometer ist kaum etwas grundsätzlich Neues. Der völlig natürliche Körper ist seit jeher eine romantische Idee.

Unsere Haut ist nicht mehr nur der Ort, an dem wir uns als schön präsentieren wollen. Unsere Haut soll immer mehr von unserem Leben, unserer eigenen Geschichte, unserem Selbst spiegeln: unseren Stil, unsere Überzeugungen, auch unsere Krankheiten. Auf diese Art verschwimmen nun auch die Grenzen zwischen Medizin und Schmuck.

«Plugs», «Tunnels» und «Freestyles» sind aus dieser Sicht keine so unterschiedlichen Sachen. Ich könnte mir vorstellen, dass ein Glukometer auch irgendwann in den geweiteten OhrläppchenPiercings seinen Platz findet.

Bildnachweis

() Mila130189| Dreamstime.com 